\title{
Patients' experiences of natalizumab treatment in a home environment: a qualitative study
}

\section{AUTHORS}

MAHASEN JUATON RN BSN M. Nursing, M. Clinical Science candidate ${ }^{1}$

LYNETTE CUSACK RN PhD MHA BN DN and Mid Cert $(\mathrm{UK})^{1}$
TIM SCHULTZ BA BSc (Hons) Grad Dipl. (Publ. Hlth) $\mathrm{PhD}^{1}$

1. Adelaide Nursing School, Faculty of Health and Medical Sciences, University of Adelaide. Adelaide, Australia.

\section{CORRESPONDING AUTHOR}

MAHASEN JUATON, Adelaide Nursing School, Faculty of Health and Medical Sciences, University of Adelaide. Level 4, Adelaide Health \& Medical Sciences Building, Corner North Terrace \& George Street. Adelaide, SA. 5005. Phone: +61421840 612. Email: mahasen.juaton@adelaide.edu.au

\section{ABSTRACT}

Objective: This study's objective was to understand the experiences and perspectives of people with multiple sclerosis who received infusions of natalizumab at home instead of the tertiary hospital day unit.

Background: Continually returning once every four weeks to an out-patient department to complete an intravenous infusion can be taxing for chronic disease patients. In Australia, acute care patients may be offered hospital in the home service. In-home services are delivered by highly qualified, trained nurses following the infusion protocols similar to that of the hospital. However, this service is not yet offered for chronic disease patients, such as those with relapsing remitting multiple sclerosis.

Study design and methods: An exploratorydescriptive study that incorporated face-to-face audio-recorded interviews of people with multiple sclerosis was undertaken as part of a larger study that trialled delivery of natalizumab at home instead of the hospital day unit. The interviews were conducted at the Ambulatory Care Day Unit of a hospital following a period of three natalizumab infusions in participants' homes. Twelve people with multiple sclerosis (two males and 10 females) aged between $18-56$ years participated in this study.
Results: A main theme of 'patient-centredness' that describes the positive contribution of having patients at the centre of care when delivering home infusions emerged. This encompassed three subthemes: 'in the comfort of their own home', 'convenience for patients and their families' and 'saving time and money'. Patient-centred care was an important part of the model of care because it provided flexibility for the participants in managing their home and work-life commitments.

Discussion: Although home infusion therapy requires a healthcare team approach, this study's findings demonstrated that delivering patient-centred home infusions provided satisfaction for people with multiple sclerosis. This enabled natalizumab to be delivered at patients' preferred time in the convenience of their own home.

Conclusion: If models of care are to be truly patientcentred, the convenience of the location of the delivery of safe treatment must be a consideration into the future design of services for those with long term health issues such as multiple sclerosis.

Implications for research, policy, and practice: Patients should play a role in the planning of their care and infusion nurses should be flexible in 
negotiating and delivering appropriate care. Future research could consider the experiences of the home infusion team.

Key words: Multiple sclerosis, model of care, patientcentred, home infusion, hospital infusion

\section{What is already known about the topic?}

People with multiple sclerosis come to hospital on a four-weekly basis to receive natalizumab infusions via an out-patient department service.
Home infusion programs have been established to stem the increasing demand for acute care hospital beds.

What this paper adds:

Home natalizumab infusions were accepted by the participants, particularly because of the convenience involved.

The study contributes to patient-centredness of home infusions, which may improve the health and wellbeing of people with multiple sclerosis.

\section{INTRODUCTION}

Out-patient intravenous therapy service is well established and is considered to be a standard of care for antimicrobial therapy. ${ }^{1}$ However, improved care for chronic disease patients who receive regular intravenous therapy should emphasise minimising and avoiding out-patient hospital admissions, so that patients do not miss work or other activities on the day of their infusion therapy. ${ }^{2}$ Around 2.5 million people have been diagnosed with multiple sclerosis (MS) worldwide, including over 23,00o people in Australia., 4 One of the first targeted disease-modifying therapies approved for the treatment of adults with Relapsing Remitting Multiple Sclerosis (RRMS) is natalizumab..$^{-8}$

\section{BACKGROUND}

Internationally, home infusion treatment programs have been established to stem the increasing demand for acute care hospital beds, decrease the risk of infections and control costs. ${ }^{9}$ From the patient's perspective, the convenience that comes with having therapy in the home is an essential benefit. Patients who received treatment through such programs reported that it is far more convenient compared to the hospital and that people with chronic health conditions experience benefits while receiving care in their own home..$^{10}$ Others emphasised that the calmness of the home environment and good home coordination provided a lesser impact on patients' lives that resulted in a positive patient experience., ${ }^{211}$ This 'convenience' links to patients' acceptance of home infusions. ${ }^{12}$ In the Australian healthcare system, acute care patients may be offered 'hospital in the home' (HITH) service. ${ }^{13}$ However, this service is not yet offered for chronic disease patients such as those with RRMS. In other countries, this practice is accepted for other monoclonal antibody agents, such as infliximab therapy, with clear advantages in terms of safety, satisfaction and cost. ${ }^{14}$ Other recent international studies have published abstracts for natalizumab home infusions. In the United Kingdom, a pilot study concluded significantly higher levels of satisfaction with home infusion service on 10 MS patients. ${ }^{15}$ Although natalizumab was well-tolerated with a positive safety profile, less serious adverse events, such as elevated temperature, were well-documented. Another study in Australia has documented the first at-home natalizumab infusion service in which 34 patients received nearly 494 doses in total at home. ${ }^{16}$ This study concluded that participants' satisfaction was achieved without compromising their safety; while this is an important finding due to the potential for adverse events early in natalizumab treatment, further detail about participants' experiences is unknown.

However, patients receiving natalizumab therapy have the risk of developing progressive multifocal leukoencephalopathy (PML), which is an infectious disease caused by the John Cunningham virus that causes progressive damage or inflammation of leukocytes within the central nervous system. ${ }^{17}$ Despite the chance of developing PML, natalizumab is a favourable treatment option for adults with highly active RRMS. ${ }^{5-7,18}$ The potential benefits of decreasing the progression of disability, stabilising the neurological symptom and increasing the quality of life must be weighed against the risk associated with PML.

Offering in-home natalizumab infusion could improve the quality of life, enhance patient centredness, and allow people with RRMS to fulfil basic daily activities. Having the patient at the centre of care should be beneficial in meeting their needs. Patient-centred care is defined as 'providing care that is respectful of, and responsive to, individual patient preferences, needs and friends, and values, and ensuring that patient values guide all clinical decisions' ${ }^{19}$ One North American study used phenomenological methodology to investigate the experiences of patients diagnosed with RRMS receiving natalizumab infusions in clinical settings. ${ }^{18}$ The study showed that participants felt that natalizumab treatment improved their quality of life. However, no previous report has focused on patients' experiences having the natalizumab infusion at their own home. In order to explore and describe the participants' experiences and perspectives of home infusion, the research question: 'What are the patients' experiences of natalizumab treatment in a home environment?' guided the study. 


\section{METHOD}

This paper presents the qualitative component of a larger study on the safety and clinical effectiveness, acceptability and cost effectiveness of home infusions of natalizumab for people with multiple sclerosis. ${ }^{20,21}$ An exploratory, descriptive approach to explore the patients' experiences of receiving treatment at home and to generate a descriptive understanding of this phenomenon was used. A descriptive understanding in the qualitative study is the exploration of human experiences to either investigate new ideas or increase knowledge of a phenomena. Schneider explained this context as 'an 'overarching' process whereby researchers do not adopt a traditional philosophical or theoretical methodological stance but, instead, use a 'free form' approach that adopts general principles of qualitative process, such as common data collection and data analysis styles'. ${ }^{22}$

\section{SETTING AND PARTICIPANTS}

The study was based in an Ambulatory Care Day Unit (ACDU), an 11 bed out-patient unit of a major metropolitan hospital in Adelaide, Australia, catering to approximately 26 out-patients per day. Ethical approval was provided by the Royal Adelaide Hospital Ethics Committee (HREC/16/RAH/192). Using convenience sampling 12 participants were selected from 37 consenting participants from the larger study, recruited using the following inclusion criteria:

- Adult MS patients ( $\geq 18$ years)

- Medically stable

- Have been risk assessed as safe for the flexible infusion delivery program by the prescribing Neurologist

- The patient has had a minimum of six natalizumab infusions

- John Cunningham Virus negative

- Comply with other vigilance requirements - Tests such as, MRI are done to identify the disease activity. In addition to clinical signs and symptoms, new lesions found in MRI indicate relapse and disability progression. ${ }^{23}$

- Have completed three natalizumab infusions at home as part of the larger study

\section{DATA COLLECTION/ANALYSIS}

A semi-structured interview was carried out during the participants' natalizumab infusions at ACDU, as this was a convenient location for participants to be interviewed. The interviews took between 20 and 60 minutes and were audiotaped. While most interviews were carried out within two months of the participants' last home infusion, a few interviews occurred more than two months after the last in-home infusion, due to the participants' appointment times and the researcher's availability. The recordings were transcribed and the transcripts were analysed using Braun and Clarke's approach to identify, analyse and report the main findings. In other words, the researcher focused on the content of the transcripts, then identified common themes. ${ }^{24}$ This approach involved grouping of concepts, supported with quotes from the participants' interviews. The transcripts were also reviewed and themed by a second researcher to build in a trustworthiness measure.

\section{FINDINGS}

\section{DEMOGRAPHICS CHARACTERISTICS}

Twelve multiple sclerosis patients participated in the faceto-face interview. Most participants were female $(n=10)$, married, and aged 36-45 years (Table 1 ).

\section{TABLE 1: DEMOGRAPHIC CHARACTERISTICS OF 12 INTERVIEW PARTICIPANTS}

\begin{tabular}{|l|l|l|}
\hline Characteristics & Nule & Number \\
\hline \multirow{3}{*}{ Gender } & Female & 2 \\
\hline \multirow{5}{*}{ Age range } & $18-25$ & 10 \\
\hline \multirow{3}{*}{ Marital status } & $26-35$ & 1 \\
\hline & $36-45$ & 2 \\
\hline & $>46$ & 6 \\
\hline \multirow{5}{*}{ Work status } & Single & 3 \\
\cline { 2 - 3 } & Married & 3 \\
\hline & Divorced & 7 \\
\hline & Widow & 2 \\
\hline & Yes & 0 \\
\hline & No & 5 (Part time) \\
\hline
\end{tabular}

\section{THEMATIC ANALYSIS}

A main theme of 'patient-centredness' emerged. This described the participants' overall experience of natalizumab infusion at home instead of the tertiary hospital. This encompassed three subthemes; in the comfort of their own home, convenience for patients and their families and saving time and money.

\section{Main theme: Patient-centredness}

All participants acknowledged that it was a positive experience not only for themselves but also for their family members. The nursing care was responsive to them as an individual and not just the treatment of the condition. Priorities were focused on patients' and their families' needs and acknowledgement of patient autonomy and involvement in determining the timing and location of their care.

\section{Subtheme one: In the comfort of their own home}

This sub-theme explains what it means for participants to have natalizumab as an option of care at home. Participants 
expressed the advantages of being comfortable during treatment at home because it fitted in with their daily routine such as having family around.

'Yeah, in my favourite chair, with my feet up, with a cup of coffee and kids - my daughter was making coffee, and my granddaughter was just playing with her toys.'(ID 11)

All of the participants expressed that they had a more pleasant experience receiving natalizumab infusion at home. Participants were very appreciative of having this model of care as an option, as one participant mentions:

'It has been a really pleasurable experience, so thank you for including me. Yeah, definitely, it's been a great experience for me.'(ID 34)

Although the participants identified advantages of having the infusion at home, one particular participant mentioned that there was a benefit of having the treatment at hospital, which allowed the participant to separate their MS condition from their home life:

'...at the moment having it at the hospital, I come to the hospital and I think about MS when I'm at the hospital but when I go home I don't have to think about it anymore.'(ID 5)

One of the consistent feelings expressed by participants was of being less stressed while having treatment at home. This was because attending hospital for an appointment and then returning home did have particular anxieties for some participants that caused them to feel stressed:

'At home, it's less stressful. I suppose it's just you're in an environment that you know. So up here [hospital], it's not so much the stress once you get here, it's the stress of getting here and then getting home too.'(ID 46)

When exploring the benefits of the home model of care, participants indicated that being at home was less stressful because they felt more relaxed and calmer.

'It was just nice and relaxed. I could just get up. I could have my water,... prepare myself. I didn't feel nauseous or anything.' (ID 12)

Another participant mentioned that access to the medication was more important than travelling to the hospital for the natalizumab infusion:

'Because I love the drug so much and that is my ultimate priority, as long as I get it I don't care where I get it,... that is the ultimate goal. As far as location, it really doesn't matter because .... coming here is really a no-brainer.'(ID 21)

\section{Subtheme two: Convenience for patients and their families}

The convenience felt by the participants was a result of ease in managing appointments which benefited them and their family members. The convenience of home infusions reduced the difficulties associated with natalizumab treatment in a hospital setting.
Participants' indicated that home infusions gave them a sense of control and autonomy over the appointment time for their therapy. Upholding dignity and integrity through decisional autonomy provides participants a sense of control over appointment times that fit into their routine, whether that be their work or home lives:

'I think I would just say it's easier to work, especially if the nurses are prepared to come later in the day, and you have your infusion before dinner or whatever, it's more convenient for your work.'(ID 3 )

To some extent, managing appointments fundamentally helped participants to maintain a sense of control over their lifestyle:

'Having it in a time that I can manage and help manage my family life is important. Yeah, so I can make the treatment fit in with my life, rather than my life fitting in around my treatment.' (ID 34)

It is clear from participants' experience that having home infusions benefits everyone. Some participants viewed home care as freeing up space at the hospital for people who are acutely ill.

'It benefits, I think, everyone. It benefits the patients, but it also benefits the hospital because there's three or four people that in a day, I suppose, I don't know how many would come up on the same day. But it just frees up that space as well.'(ID 46)

Another participant highlighted the benefits at workplace.

'As I said about [my work], I didn't have to leave early and disappoint the [students], or get a reliever or anything like that.' (ID 5)

Others mentioned that having home infusions was suitable for their family commitment, as they could continue with their usual daily activities in their own environment.

'...You probably get the same from everybody. It was really convenient with my lifestyle, with work and kids and everything.'(ID 20)

\section{Subtheme three: Saving time and money}

Although a natalizumab infusion only takes an hour in a hospital setting, most of the participants claimed that it is almost a day spent in hospital. Some participants or their family members need to take a day off work to accommodate the treatment. This will then impact on them having to make up the day lost or have lesser pay. Others have to spend extra money to have their children looked after by a carer during treatments. This subtheme documents the participants' perceptions of home infusions in terms of the saving time and money.

Most of the participants reported that they felt that the infusion went 'quicker' compared to the hospital service. 
'So yeah, I think it - it went fairly quickly anyway but I think it went quicker because I wasn't sort of aware of it as much.'

(ID 34)

Travelling time represents the participants' experience of travelling to and from the hospital for their appointment, which was an issue that all participants verbalised. Most of the participants were also concerned about parking their car, the level of traffic on the inner city roads, and rushing to the hospital to be on time for appointments. Participants indicated that one of the main benefits of the home model of care was eliminating the need to travel to and from the hospital:

'...You don't have to worry about the time it takes to travel in and to travel home. I much prefer it at home.'(ID 11)

Saving money is one of the benefits identified from receiving home infusions. Participants mentioned that staying at home was beneficial as they do not have additional costs for petrol, parking, television rental and food.

'You're spending less money on petrol and parking, which is a big drama.'(ID 3 )

In addition, they also mentioned that they did not need to take time 'off' from work, which also related to costeffectiveness.

'I think that - so it didn't cost me anything to be able to have it at home.'(ID 5)

\section{DISCUSSION}

Patients' perspectives and evaluation of service delivery within the healthcare system should be focused on what they find important. ${ }^{2,25}$ Ducharme, Pelletier and Zacharias have reported that 'restrictions' and 'inefficient care' leads to inconvenience for patients. ${ }^{26}$ Trialling a model of care for home infusions of natalizumab, which was the focus of the larger study, was in response to the changing expectations of patients' as well as the evidence of the safe infusion of natalizumab in the community away from the acute health service. The findings from this study aided the understanding of how people with MS appreciated and benefited from the care provided. This was supported by the participants' interviews and their aspiration of having a permanent home infusion delivery. Overall, the study indicated that being at home while receiving natalizumab infusions supported a patient-centred care approach by offering convenience for patients with RRMS and their family members. In addition, this provides a valuable insight for nurses delivering in-home treatment. Given the pivotal role of nurses within an in-home service, further qualitative study exploring their experiences with the concept of patient-centred model of care would be beneficial.

\section{PATIENT-CENTREDNESS}

In our study, the flexibility and ease in which the participants could arrange their appointments' was highlighted. They were able to make re-bookings easily by messaging the infusion nurse and having their natalizumab treatment at an agreed time and place. One of the dimensions of the MS relapse management scale to measure patient care is 'access to care'. ${ }^{2}$ During the participants' home infusions, they mentioned that they had their four-weekly infusions in a time and place that suits them, as the home infusion team upheld flexibility with the appointments. Also, they noticed that the infusion went quicker compared to the ones at the hospital. This may be due to the 1:1 ratio of patient-nurse in the home, therefore enabling the immediate and total attention of the nurse, where the main focus was patients' safety and comfort. The home treatment was more physically and emotionally comfortable. This finding is supported by international studies, which found that because of the initial impression of comfort, the majority of participants elected to change to in-home infusions. ${ }^{2,10-12}$

The second dimension of the MS relapse management scale is 'coordination of care', which relates to this study's subthemes 'in the comfort of their own home', which emphasised the advantages of participants being more comfortable and less stressed in their own home during the treatment. This is consistent with findings from other home therapy survey studies. In Italy, a survey of adults receiving enzyme replacement therapy for lysosomal storage disease found that the majority of participants favoured in-home therapy, indicating that they experienced less stress, increased comfort and less impact on family life during the treatment. ${ }^{27}$ Given the relationship between stress (at work or life events) and relapse for people with $\mathrm{MS},{ }^{28}$ reduced stress may reduce the risk of relapse, which is very important to patients with MS.

Acknowledging patients' comfort and empowering patients' and family members' involvement with the plan of care can lead to a higher level of patient compliance with their treatment. ${ }^{29}$ Consistent with the trends in other in-home treatment models, convenience for patients and their families made a significant difference to their experiences of infusion therapy in the home setting. A number of studies have demonstrated that receiving IV therapy at home will increase patient compliance with their treatment. ${ }^{11,29-31}$ Being in hospital for infusions presents obstacles for MS patients, which may be addressed by providing alternative services, such as infusion therapy at home. 


\section{LIMITATIONS}

The participants of this study consisted of RRMS patients who were currently receiving infusions at a single, metropolitan, tertiary hospital. The results may not be generalisable to other groups of patients and other MS patients at other hospitals and countries due to geographic and social differences.

\section{CONCLUSION}

This is the first research on the experiences of people with MS receiving natalizumab in the home environment. This study supports health services to consider different models of delivering care for patients with chronic conditions, such as MS, requiring regular infusions. Delivering the infusion in an environment of the patient's choice does enhance their wellbeing, physically, emotionally and financially. The convenience, comfort and saving time and money of in-home treatment were the most important parts of the experience that contributed to a patient-centred approach. Therefore, this study encourages adopting in-home infusion therapy as an ongoing model of care to support MS patients' health and wellbeing within their own familiar environment, ensuring their lifestyle remains as routine as possible.

\section{RECOMMENDATIONS}

To ensure patient-centredness, the infusion nurses and the support team should discuss the patients' and families' needs when receiving infusions in the home. Depending on the situation, patients should play a role in the planning of their care and infusion nurses should be flexible in planning and delivering the care. The study recommends important areas for future research, including:

As patients only were included, in future studies it would be useful to understand the experiences and opinions of their family members, including their involvement in care, using in-depth interview tools.

It would be beneficial to further explore if there are any additional benefits of home care to supporting the broader family unit.

It would also be useful to consider the experiences of the inhome infusion team during the period of in-home infusions.

Funding support: The research was funded by Biogen Australia and New Zealand as investigator-initiated research.

Declaration of conflicting interests: All authors declare that they have no conflict of interest in relation to this work.

\section{REFERENCES}

1. Tice A, Rehm S, Dalovisio J, Bradley J, Martinelli L, Graham D, et al. Practice guidelines for outpatient parenteral antimicrobial therapy. IDSA guidelines. Clin Infect Dis. 2004; 38(12): 1651-72.

2. Chataway J, Porter B, Riazi A, Heaney D, Watt H, Hobart J, et al. Home versus outpatient administration of intravenous steroids for multiple-sclerosis relapses: a randomised controlled trial. Lancet Neurol. 2006; 5(7): 565-71.

3. Compston A, Coles A. Multiple sclerosis. Lancet Neurol. 2002; 372: 1502-17.

4. Kornek B. An update on the use of natalizumab in the treatment of multiple sclerosis: Appropriate patient selection and special considerations. Patient Prefer Adherence. 2015; 9: 675-84.

5. Kappos L, Bates D, Hartung H, Havrdova E, Miller D, Polman $C$, et al. Natalizumab treatment for multiple sclerosis: recommendations for patient selection and monitoring. Lancet Neurology. 2007; 6(5): 431-41.

6. McCormack PL. Natalizumab: a review of its use in the management of relapsing-remitting multiple sclerosis. Drugs. 2013; 73(13): 1463-81.

7. Nicholas J, Racke M, Imitola J, Boster A. First-line natalizumab in multiple sclerosis: rationale, patient selection, benefits and risks. Ther Adv Chronic Dis. 2014; 5(2): 62-8.

8. Stuve $\bigcirc$. Knowns and unknowns in the future of multiple sclerosis treatment. J Neurol Sci. 2009; 287: S30-6.

9. Snelling M. Home intravenous therapy. Hospital Pharmacist. 2008;15(1):16

10. Stephens B. Patients' experiences of community IV therapy. Br J Nurs. 2013; 22(19): S24-7, S9.

11. Milligan A, Hughes D, Goodwin S, Richfield L, Mehta A. Intravenous enzyme replacement therapy: better in home or hospital? Br J Nurs. 2006; 15(6): 330

12. Beijer S, Wijckmans N, Rossum E, Spreeuwenberg C, Winkens $\mathrm{R}, \operatorname{Ars} \mathrm{L}$, et al. Treatment adherence and patients' acceptance of home infusions with adenosine 5 '-triphosphate (ATP) in palliative home care. Support Care Cancer. 2008; 16(12): 1419-24.

13. Gardner G, Gardner A, Morley G, Watson DA. Managing intravenous medications in the non-hospital setting: an ethnographic investigation. J Infus Nurs. 2003; 26(4): 227-33.

14. O'Connor P, Goodman A, Willmer-Hulme A, Libonati M, Metz L, Murray $R$, et al. Randomized multicenter trial of natalizumab in acute MS relapses: clinical and MRI effects. Neurology. 2004; 62(11): 2038-43.

15. Brex P, Ford H, Silber E, Thomas F. MS patients' satisfaction with a home infusion service: a pilot study. J Neurol Neurosurg Psychiatry. 2017; 88:A41.

16. Vijayan S, Adams J, Cook L, Haskins Z, Kermode A. Establishment of the first at-home natalizumab infusion service for the treatment of relapsing remitting multiple sclerosis (rmms). J Neurol Neurosurg Psychiatry. 2017; 88(5): e1.

17. Ferenczy M, Marshall L, Nelson C, Atwood W, Nath A, Khalili $K$, et al. Molecular biology, epidemiology, and pathogenesis of progressive multifocal leukoencephalopathy, the JC virusinduced demyelinating disease of the human brain. Clin Microbiol Rev. 2012; 25(3): 471-506.

18. Miller C, Karpinski M, Jezewski M. Relapsing-remitting multiple sclerosis patients' experience with natalizumab: a phenomenological investigation. Int J MS Care. 2012; 14(1): 39-44 
19. Institute of Medicine. Crossing the Quality Chasm: A New Health System for the 21st Century. Washington, DC: The National Academies Press; 2001.

20. Schultz T, Thomas A, Georgiou P, Juaton M, Simon L, Cusack $L$, et al. Piloting home infusions of natalizumab: a randomised crossover trial. J Neurol Neurosurg Psychiatry Res. 2018; 89(6): A10.

21. Schultz TJ, Thomas A, Georgiou P, Cusack L, Juaton M, Simon $L$, et al. Developing a Model of Care for Home Infusions of Natalizumab for People With Multiple Sclerosis. J Infus Nurs. 2019; 42(6): 289.

22. Schneider Z. Nursing and midwifery research methods and appraisal for evidence-based practice / Zevia Schneider ... [et al.]. 4th edition. ed. Whitehead D, LoBiondo-Wood G, Haber J, editors: Chatswood, N.S.W. : Mosby; 2013.

23. Kappos L, Bates D, Edan G, Eraksoy M, Garcia-Merino A, Grigoriadis N, et al. Natalizumab treatment for multiple sclerosis: updated recommendations for patient selection and monitoring. Lancet Neurology. 2011; 10(8): 745-58.

24. Braun V, Clarke V. Using thematic analysis in psychology. Qual Res Psychol. 2006; 3(2): 77-101.

25. Jenkinson C, Coulter A, Bruster S, Richards N, Chandola T. Patients' experiences and satisfaction with health care: results of a questionnaire study of specific aspects of care. Qual Saf Health Care. 2002; 11(4): 335.

26. Ducharme J, Pelletier C, Zacharias R. The safety of infliximab infusions in the community setting. Can J Gastroenterol. 2010; 24(5): 307-11.

27. Parini R, Pozzi K, Di Mauro S, Furlan F, Rigoldi M. Intravenous enzyme replacement therapy: hospital vs home. Br J Nurs. 2010; 19(14): 892-8.

28. Brown RF, Tennant CC, Sharrock M, Hodgkinson S, Dunn SM, Pollard JD. Relationship between stress and relapse in multiple sclerosis: Part I. Important features. Mult Scler. 2006; 12(4): 453-64.

29. Cousins A, Lee P, Rorman D, Raas-Rothschild A, Banikazemi M, Waldek $\mathrm{S}$, et al. Home-based infusion therapy for patients with Fabry disease. Br J Nurs. 2008; 17(10): 653.

30. Berntorp E, Lethagen S. The role of home infusion therapy in haemophilia: a disease management perspective. Dis Manag Health Out. 2000; 7(2): 77-81.

31. Burton B, Guffon N, Roberts J, van der Ploeg A, Jones S. Home treatment with intravenous enzyme replacement therapy with idursulfase for mucopolysaccharidosis type II - data from the Hunter Outcome Survey. Mol Genet Metab 2010; 101: 123-9. 